\title{
Pengaruh Gaya Kepemimpinan Partisipatif dan Lingkungan Kerja Fisik Terhadap Semangat Kerja Karyawan
}

\author{
I Nyoman Partha Astinatria ${ }^{(1)}$ \\ I Wayan Gde Sarmawa ${ }^{(2)}$ \\ ${ }^{(1)(2)}$ Fakultas Ekonomi dan Bisnis Universitas Warmadewa Denpasar \\ e-mail: triaparta@gmail.com; wayangdesarmawa@gmail.com \\ \begin{tabular}{|l|l|l|}
\hline Diterima: 6 Januari 2020 & Direvisi: 27 Januari 2020 & Disetujui: 30 Januari 2020 \\
\hline
\end{tabular}
}

\begin{abstract}
The purpose of this study was to determine the effect of leadership style and physical work environment on employee morale. This research was conducted at $C V$. Dinayu convection which is located at Jalan Patih Nambi no 99, Ubung Kaja, Denpasar Utara. The population and sample of the study were all employees in the CV. Dinayu, totaling 54 people. The data collection method uses a questionnaire that generally contains respondents' perceptions of participative leadership style, physical work environment, and employee morale. Data analysis was performed with multiple regression linear tests. The results of this study indicate that the leadership and work environment variables have a positive and significant effect on employee morale in the $C V$. Dinayu conjunction convection.
\end{abstract}

Keywords: Leadership style, Physical work environment, Employee work spirit.

\section{Pendahuluan}

Sumber Daya Manusia (SDM) merupakan elemen utama organisasi dibandingkan dengan elemen lain seperti modal, teknologi dan uang, sebab manusia itu sendiri mengendalikan elemen-elemen lain. Manusia memilih teknologi, manusia yang mencari modal, manusia yang menggunakan dan memeliharanya. Dengan perkataan lain, manusia merupakan kekayaan (aset) yang paling utama dan sangat strategis yang dimiliki oleh suatu organisasi.

Gaya kepemimpinan partisipatif adalah pendelegasian wewenang terdesentralisasi, keputusan yang diambil pemimpin melibatkan opini dari bawahan, komunikasi pemimpin dan bawahan dua arah, berorientasi pada hubungan, asumsi pada karyawan karyawan dapat bekerja sama dan bermoral, perencanaan tujuan dilakukan oleh keterlibatan karyawan (Andre Setiawan: 2017).

Berdasarkan kenyataan yang terjadi dapat dijelaskan beberapa masalah yang terjadi berkaitan dengan kepemimpinan adalah pimpinanan yang jarang melibatkan bawahannya dalam mengambil keputusan, pimpinan kurang memberi arahan kepada para karyawan, 
pemimpin jarang memotivasi karyawan, jadi secara garis besar komunikasi pemimpin terhadap karyawan yang menjadi masalah.

Lingkungan kerja fisik adalah segala sesuatu yang ada di sekitar pekerjaan yang dapat mempengaruhi dirinya dalam menjalankan tugas-tugas yang dibebankan. Di dalam menciptakan lingkungan kerja fisik agar dapat meningkatkan aktifitas perusahaan, maka di perlukan pengaturan lingkungan kerja fisik seperti udara, suara, cahaya, warna, ruang gerak, kebersihan dan keamanan (Martoyo, 2011: 108).

Semangat kerja adalah istilah yang menyangkut keperluan diluar pekerjaan seperti pendapatan, rasa aman dan kedudukannya yang lebih tinggi dalam masyarakat, keputusan terhadap pekerjaan misalnya minat kerja, peluang untuk maju didalam perusahan, kepuasan pribadi dan rasa bangga atas profesinya" (Nitisemito dalam Yoga, 2011:38)

CV. Dinayu Konveksi merupakan sebuah perusahaan konveksi yang bergerak dalam bidang konveksi dan mempunyai jumlah karyawann sebanyak 54 orang. Sesuai dengan pendiriannya CV. Dinayu Konveksi yang bergerak dalam bidang produksi pakaian sebagai bahan bakunya. Produk yang ditawarkan diantaranya adalah baju sekolah (SD dan SMP), baju kantor, Baju Kaos, jaket, treining dan lain sebagainya. Semua produk ini diproduksi sesuai dengan konsumen yang diinginkan.

Dengan demikian sudah selayaknya karyawan diperlukan secara layak dan adil sesuai dengan apa yang telah diberikannya kepada perusahaan, yang dapat berimplikasi kepada timbulnya semangat kerja. Setiap perusahaan selalu berusaha meningkatkan semangat kerja semaksimal mungkin dalam batas-batas kemampuan perusahaan. Apabila perusahaan lalai memperhatikannya maka semangat kerja turun.

Peneitian ini bertujuan untuk mengetahui pengaruh gaya kepemimpinan partisipatif secara positif dan signifikan terhadap semangat kerja karyawan CV. Dinayu Konveksi Ubung; untuk mengetahui pengaruh lingkungan kerja fisik secara positif dan signifikan terhadap semangat kerja karyawan CV. Dinayu Konveksi Ubung; dan untuk mengetahui pengaruh variabel gaya kepemimpinan partisipatif dan lingkungan kerja fisik secara bersama-sama (simultan) terhadap semangat kerja karyawan. CV. Dinayu Konveksi Ubung.

\section{Telaah Literatur dan Kajian Pustaka}

Kepemimpinan adalah sebagai suatu proses pengarahan dan pemberian pada kegiatankegiatan dari sekelompok anggota yang saling berhubungan tugasnya (Stoner dalam Yoga, 2011:36). Dari definisi di atas dapat disimpulkan bahwa kepemimpinan kemampuan setiap pimpinan dalam mempengaruhi dan menggerakkan bawahannya sedemikian rupa sehingga 
para bawahannya bekerja dengan rasa bergairah, bersedia bekerja sama dan mempunyai disiplin yang mendorong mereka tujuan tertentu.

Lingkungan kerja fisik adalah Segala sesuatu yang ada di sekitar pekerja dan yang dapat mempengaruhi dirinya dalam menjalankan tugas-tugas yang dibebankan" (Nitisemito,2013:109). Seperti yang diuraikan di atas bahwa lingkungan kerja berpengaruh terhadap kerja karyawan dalam melaksanakan tugas mereka. Ini berarti berusaha menciptakan suasana lingkungan kerja sesuai keinginan dari karyawan yang melaksanakan tugas pada suatu tempat kerja di dalam mencapai tujuan yang diinginkan perusahaan.

Semangat kerja adalah istilah yang menyangkut keperluan diluar pekerjaan seperti pendapatan, rasa aman dan kedudukannya yang lebih tinggi dalam masyarakat, keputusan terhadap pekerjaan misalnya minat kerja, peluang untuk maju didalam perusahan, kepuasan pribadi dan rasa bangga atas profesinya" (Nitisemito dalam Yoga, 2011:38). Berdasarkan penjelasan diatas dapat disimpulkan bahwa semangat kerja yang baik dapat terlihat apabila para karyawan nampaknya merasa senang, optimis terhadap semua kegiatan-kegiatan dan tugastugas serta ramah tamah satu sama lainnya.

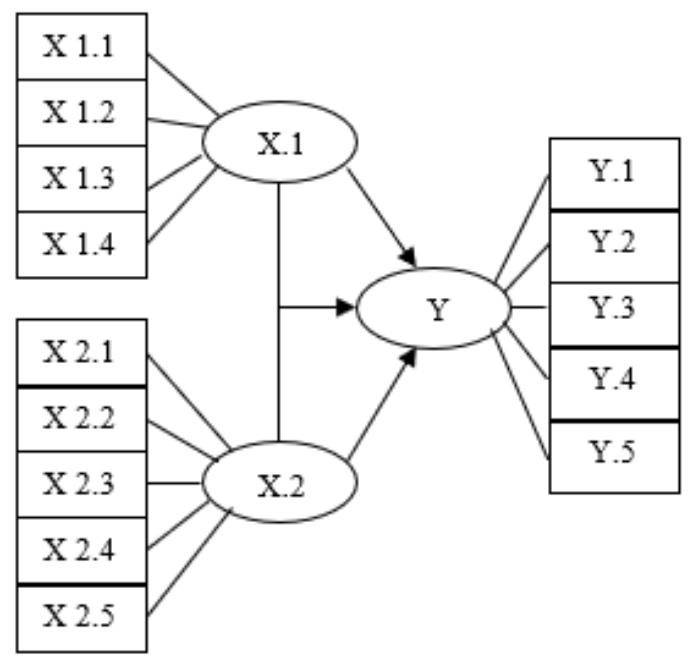

Gambar 1. Kerangka Peneelitian

Keterangan:

Sumber X1 : Kepemimpinan Partisipatif

X2 : Lingkungan Kerja Fisik

Y : Semangat Kerja Karyawan

Keterangan:

1. Semangat Kerja Karyawan (Y)

Y.1: Produktivitas 
Y.2: Absensi

Y.3: Tingkat Kerusakan

Y.4: Kegelisahaan

Y.5: Tuntutan

2. Kepemimpinan Partisipatif (X1)

X1.1: Cara berkomunikasi

X1.2: Pemberian motivasi

X1.3: Kemampuan memimpin

X1.4: Pengambil keputusan

3. Lingkungan Kerja Fisik (X2)

X2.1: Keamanan

X2.2: Kebersihan

X2.3: Penerangan

X2.4: Kebisingan

X2.5: Warna

Hipotesis yang dirumuskan dalam penelitian ini adalah, H1: variabel gaya kepemimpinan partisipatif berpengaruh positif dan signifikan terhadap semangat kerja karyawan pada CV. Dinayu Konveksi Ubung; H2: variabel lingkungan kerja fisik berpengaruh positif dan signifikan terhadap semangat kerja karyawan pada CV.Dinayu Konveksi Ubung; dan H3: variabel gaya kepemimpinan partisipatif dan lingkungan kerja fisik secara bersama-sama berpengaruh positif dan signifikan terhadap semangat kerja karyawan pada CV. Dinayu Konveksi Ubung.

\section{Metode Penelitian}

Lokasi penelitian adalah CV. Dinayu Konveksi Ubung jalan patih nambi no 99 ubung kaja denpasar utara, Bali, dengan obyek penelitian adalah kepemimpinan dan lingkungan kerja fisik dikaitkan dengan semangat dan kegairahan kerja karyawan pada CV. Dinayu Konveksi Ubung.

Menurut Sugiyono (2014:80) mendefinisikan populasi adalah wilayah generalisasi yang terdiri atas: obyek/subyek yang mempunyai kualitas dan karakteristik tertentu yang yang diterapkan oleh peneliti untuk dipelajari dan kemudian ditarik kesimpulan. Responden dalam penelitian seluruh karyawan yang berjumlah 54 orang karyawan yang tersebar pada bagian yang ada. Hal ini diambil mengingat pada masing-masing bagian jenis pekerjaan relatif berbeda. 
Sampel menurut Arikunto (2006:112) yang menyatakan bahwa "jika objeknya kurang dari 100, lebih baik diambil semua sehingga penelitiannya merupakan penelitian populasi. Populasi yang ada pada CV. Dinayu Konveksi Ubung berjumlah 54 orang jadi dalam penelitian ini diambil seluruh jumlah populasi yang ada. Jadi bisa dikatakan jenis penelitian ini adalah penelitian sensus.

Metode Analisis Data

- Uji Instrumen, yaitu dengan uji validitas dan reliabilitas

Validitas adalah suatu ukuran yang menunjukkan tingkat kesahinan suatu tes. Suatu tes dikatakan valid apabila tes tersebut mengukur apa yang hendak diukur. Uji validitas dilakukan untuk mengukur sah atau valid tidaknya suatu kuesioner. jika Rhitung > Rtabel berarti item valid. Sebaliknya, jika Rhitung < Rtabel berarti item tidak valid. Hasil Rhitung kita bandingkan dengan Rtabel dimana $\mathrm{df}=\mathrm{n}-2$ dengan sig $5 \%$.

Uji Reliabilitas merupakan ukuran suatu kestabilan dan konsistensi responden dalam menjawab hal yang berkaitan dengan pertanyaan yang merupakan dimensi suatu variabel dan disusun dalam suatu bentuk kuesioner. Reliabilitas menunjukkan bahwa kuesioner tersebut konsisten apabila digunakan untuk mengukur gejala yang sama di lain tempat.

- Uji Asumsi Klasik, meliputi uji normalitas, uji multikolinearitas, dan uji heteroskedastisitas.

Uji normalitas bertujuan untuk menguji apakah dalam model regresi, terdapat variabel pengganggu atau residual yang memiliki distribusi normal. Untuk mendeteksi normalitas data, pada penelitian ini akan dilakukan uji statistik. Apabila nilai probabilitas signifikan K S > 5\% atau 0.05, maka data berdistribusi normal (Husein Umar, 2011:180).

Uji multikolinearitas digunakan untuk mengetahui ada tidaknya multikolinearitas dengan menyelidiki besarnya inter korelasi antar variavel bebasnya. Ada tidaknya mutikolinearitas dapat dilihat dari besarnya Tolerance Value dan Variance Inflation Factor (VIF). Jika nilai Tolerance Value $>0,10$ atau sama dengan nilai VIF $<10$.

Uji heteroskedastisitas dilakukan untuk menguji apakah dalam model regresi terjadi ketidaksamaan residual antara satu pengamatan dengan pengamatan yang lain. Apabila Variance dari residual satu pengamatan ke pengamatan lain tetap, maka disebut homoskedastisitas sedangkan jika Variance dari residual antara pengamatan satu dengan lainnya berbeda disebut heteroskedastisitas. Apabila variabel independen signifikan secara statistik tidak mempengaruhi variabel dependen maka tidak terdapat indikasi terjadinya 
heteroskedastisitas. Hal ini dapat dilihat apabila dari probabilitas signifikasinya di atas tingkat kepercayaan $5 \%$.

- Analisis regresi linier berganda yang digunakan untuk mengetahui berubahnya semangat kerja karyawan (Y) yang dipengaruhi oleh variable bebas yaitu gaya kepemimpinan partisipatif (X1) dan lingkungan kerja fisik (X2), Dengan rumus sebagai berikut (Sugiyono, 2014:275).

$\mathrm{Y}=\mathrm{a}+\mathrm{b} 1 \mathrm{X} 1+\mathrm{b} 2 \mathrm{X} 2$

Dimana :

$\mathrm{Y}=$ Semangat kerja karyawan

a $\quad=$ Konstan

$\mathrm{X} 1=$ Gaya Kepemimpinan Partisipatif

X2 = Lingkungan Kerja Fisik

$\mathrm{b} 1=$ Koefisien regresi dari $\mathrm{X} 1$

b2 $=$ Koefisien regresi dari X2

- $\quad$ Uji F (F-test) untuk menguji keberartian korelasi antara dua variabel bebas terhadap suatu variabel terikat secara bersama-sama dengan rumus sebagai berikut : (Sugiyono, 2014:182)

$$
\begin{aligned}
& \text { F-test }=\frac{\mathrm{R}^{2} / \mathrm{k}}{\left(1-\mathrm{R}^{2}\right) /(\mathrm{n}-\mathrm{k})} \\
& \text { Dimana : } \\
& \mathrm{R} \quad=\text { Koefisien korelasi berganda } \\
& \mathrm{n} \quad=\text { Jumlah sampel } \\
& \mathrm{k} \quad=\text { Jumlah variabel bebas }
\end{aligned}
$$

- Analisis t-test, bertujuan untuk membuktikan apakah korelasi yang diperoleh antara variabel memang benar atau didapat secara kebetulan, digunakan rumus (Sugiyono, 2014:177)

$$
\mathrm{t}=\frac{\mathrm{bi}}{\mathrm{sbi}}
$$

\section{Dimana:}

$$
\begin{aligned}
\mathrm{t} & =\text { nilai } \mathrm{t}-\mathrm{hitung} \\
\mathrm{bi} & =\text { koefisien regresi } \\
\mathrm{sbi} & =\text { standar deviasi bi }
\end{aligned}
$$




\section{Hasil Penelitian dan Pembahasan}

Tabel 1. Hasil Uji Validitas dan Reliabilitas Instrumen Penelitian

\begin{tabular}{|c|c|c|c|c|c|}
\hline \multirow{2}{*}{ Variabel } & \multicolumn{3}{|c|}{ Validitas } & \multicolumn{2}{|c|}{ Reliabilitas } \\
\hline & Item & Koefisien korelas & keterangan & Alpha Cronbach & Keterangan \\
\hline \multirow{6}{*}{$\begin{array}{l}\text { Gaya Kepemimpinan } \\
\text { partisipatif }\end{array}$} & $\mathrm{X} 1.1$ & 0,954 & Valid & \multirow{4}{*}{0,955} & \multirow{4}{*}{ Reliabel } \\
\hline & $\mathrm{X} 1.2$ & 0,923 & Valid & & \\
\hline & $\mathrm{X} 1.3$ & 0,943 & Valid & & \\
\hline & $\mathrm{X} 1.4$ & 0,936 & Valid & & \\
\hline & $\mathrm{X} 2.1$ & 0,930 & Valid & \multirow{5}{*}{0,905} & \multirow{5}{*}{ Reliabel } \\
\hline & $\mathrm{X} 2.2$ & 0,831 & Valid & & \\
\hline \multirow[t]{3}{*}{ Lingkungan kerja fisik } & $\mathrm{X} 2.3$ & 0,725 & Valid & & \\
\hline & $\mathrm{X} 2.4$ & 0,862 & Valid & & \\
\hline & $\mathrm{X} 2.5$ & 0,907 & Valid & & \\
\hline \multirow{5}{*}{ Semangat kerja karyawan } & Y1 & 0,550 & Valid & \multirow{5}{*}{0,732} & \multirow{5}{*}{ Reliabel } \\
\hline & $\mathrm{Y} 2$ & 0,560 & Valid & & \\
\hline & Y3 & 0,554 & Valid & & \\
\hline & Y4 & 0,650 & Valid & & \\
\hline & Y5 & 0,457 & Valid & & \\
\hline
\end{tabular}

Berdasarkan Tabel 1, maka semua variabel memiliki korelasi di atas 0,3 dan nilai koefisien Alpha Cronbach berada diatas 0,6 sehingga instrumen tersebut adalah valid dan reliabel, sehingga layak dijadikan instrumen penelitian.

Tabel 2. Deskripsi Variabel Gaya Kepemimpinan Partisipatif

\begin{tabular}{|c|c|c|c|c|c|c|c|c|c|c|}
\hline \multirow{2}{*}{ No } & \multirow{2}{*}{ Indikator } & \multicolumn{5}{|c|}{ Jawaban Responden } & \multirow{2}{*}{$\begin{array}{c}\text { Jumlah } \\
\text { Responden }\end{array}$} & \multirow{2}{*}{$\begin{array}{l}\text { Jumlah } \\
\text { Skor }\end{array}$} & \multirow{2}{*}{$\begin{array}{l}\text { Rata- } \\
\text { Rata }\end{array}$} & \multirow{2}{*}{ Keterangan } \\
\hline & & 5 & 4 & 3 & 2 & 1 & & & & \\
\hline 1 & $\begin{array}{l}\text { Cara berkomunikasi } \\
\text { (X1.1) }\end{array}$ & 0 & 9 & 11 & 34 & 0 & 54 & 137 & 2,54 & Kurang Baik \\
\hline 2 & $\begin{array}{l}\text { Pemberian motivasi } \\
\text { (X1.2) }\end{array}$ & 0 & 10 & 14 & 30 & 0 & 54 & 142 & 2,63 & Cukup Baik \\
\hline 3 & $\begin{array}{l}\text { Kemampuan memimpin } \\
\text { (X1.3) }\end{array}$ & 0 & 9 & 14 & 31 & 0 & 54 & 140 & 2,59 & Kurang Baik \\
\hline \multirow[t]{2}{*}{4} & $\begin{array}{l}\text { Pengambilan keputusan } \\
\text { (X1.4) }\end{array}$ & 0 & 9 & 12 & 33 & 0 & 54 & 138 & 2,56 & Kurang Baik \\
\hline & \multicolumn{6}{|c|}{ Rata-rata } & & & 2,58 & Kurang Baik \\
\hline
\end{tabular}

Berdasarkan Tabel 2, rata-rata skor dari 4 pernyataan mengenai gaya kepemimpinan partisipatif yaitu sebesar 2,58 yang berada pada kisaran 2,60 - 3,40 yang berarti cukup baik. Hal ini berarti responden dalam penelitian ini menilai kepemimpinan partisipatif dalam keadaan baik. Pada variabel kepemimpinan partisipatif yang dinilai paling rendah oleh responden adalah cara berkomunikasi $(2,54)$.

Tabel 3. Deskripsi Variabel Lingkungan Kerja Fisik

\begin{tabular}{|c|c|c|c|c|c|c|c|c|c|c|}
\hline \multirow{2}{*}{ No } & \multirow{2}{*}{ Indikator } & \multicolumn{5}{|c|}{ Jawaban Responden } & \multirow{2}{*}{$\begin{array}{c}\text { Jumlah } \\
\text { Responden }\end{array}$} & \multirow{2}{*}{$\begin{array}{c}\text { Jumlah } \\
\text { Skor }\end{array}$} & \multirow{2}{*}{$\begin{array}{l}\text { Rata- } \\
\text { Rata }\end{array}$} & \multirow[b]{2}{*}{ Keterangan } \\
\hline & & 5 & 4 & 3 & 2 & 1 & & & & \\
\hline 1 & Keamanan (X2.1) & 0 & 31 & 15 & 5 & 0 & 54 & 191 & 3,54 & Baik \\
\hline 2 & Kebersihan (X2.2) & 0 & 31 & 21 & 2 & 0 & 54 & 191 & 3,54 & Baik \\
\hline 3 & Penerangan (X2.3) & 0 & 38 & 12 & 4 & 0 & 54 & 196 & 3,63 & Baik \\
\hline 4 & Kebisingan (X2.4) & 0 & 36 & 14 & 4 & 0 & 54 & 194 & 3,59 & Baik \\
\hline \multirow[t]{2}{*}{5} & Warna (X2.5) & 0 & 36 & 14 & 4 & 0 & 54 & 194 & 3,59 & Baik \\
\hline & \multicolumn{6}{|c|}{ Rata-Rata } & & & 3,58 & Baik \\
\hline
\end{tabular}


Berdasarkan Tabel 3, terlihat bahwa rata-rata skor dari 5 pernyataan mengenai lingkungan kerja fisik yaitu sebesar 3,58 yang berada pada kisaran 3,4 - 4,20 yang berarti kategori baik. Hal ini berarti responden dalam penelitian ini menilai lingkungan kerja fisik secara keseluruhan dalam kondisi baik. Indikator yang dinilai dengan rata-rata paling rendah pada variabel lingkungan kerja fisik adalah keamanan $(3,54)$ dan kebersihan $(3,54)$.

Tabel 4. Deskripsi Variabel Semanagat Kerja karyawan

\begin{tabular}{clccccccccc}
\hline \multirow{2}{*}{ No } & \multicolumn{1}{c}{ Indikator } & \multicolumn{1}{c}{ Jawaban Responden } & Jumlah & Jumlah & Rata- \\
& & 5 & 4 & 3 & 2 & 1 & Responden & Skor & Rata & Keterangan \\
\hline 1 & Produktivitas (Y1) & 0 & 2 & 42 & 10 & 0 & 54 & 154 & 2,85 & Cukup Baik \\
2 & Absensi (Y2) & 0 & 2 & 32 & 20 & 0 & 54 & 144 & 2,67 & Cukup Baik \\
3 & Tk. Kerusakan (Y3) & 0 & 3 & 29 & 22 & 0 & 54 & 143 & 2,65 & Cukup Baik \\
4 & Kegelisahan (Y4) & 0 & 0 & 29 & 25 & 0 & 54 & 137 & 2,54 & Kurang Baik \\
5 & Tuntutan (Y5) & 0 & 0 & 35 & 19 & 0 & 54 & 143 & 2,65 & Cukup Baik \\
& \multicolumn{8}{c}{ Rata-rata } \\
\hline
\end{tabular}

Berdasarkan tabel di atas, terlihat bahwa rata-rata skor dari 5 pernyatan mengenai semangat kerja karyawan yaitu sebesar 2,67 yang berada pada kisaran 2,60 - 3,40 yang berarti cukup baik. Hal ini berarti pada yang menjadi responden dalam penelitian ini memiliki semangat kerja karyawan adalah cukup baik. Sedangkan indikator yang bernilai paling rendah adalah kegelisahan $(2,54)$.

Tabel 5. Hasil Uji Normalitas

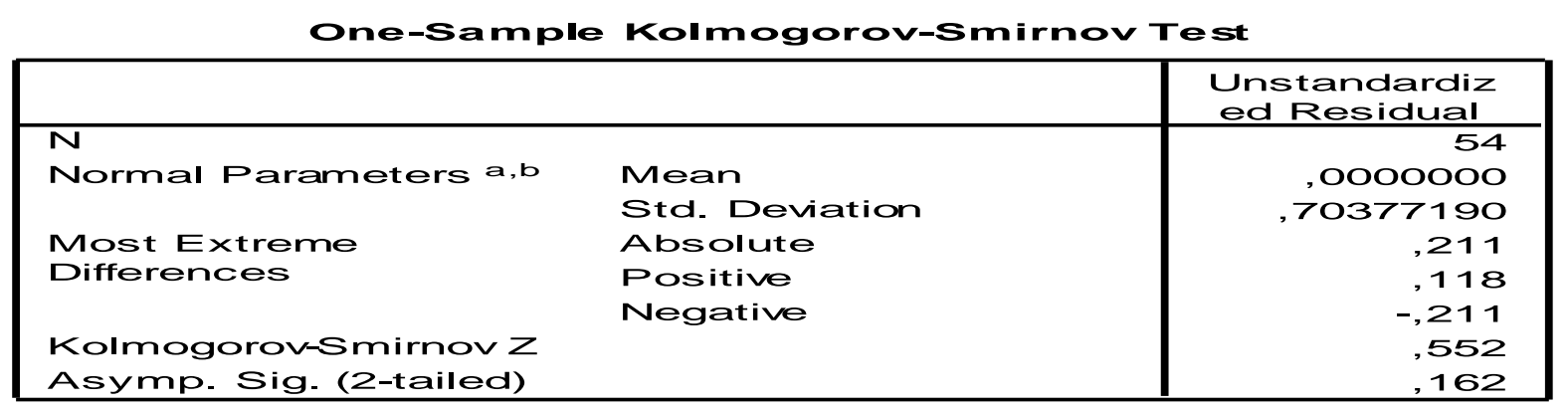

a. Test distribution is Normal.

b. Calculated from data.

Hasil uji menunjukkan bahwa nilai Asymp. Sig. 0,162. Oleh karena nilai Asymp. Sig. lebih besar dari alpha 5 persen maka, dapat dinyatakan bahwa model uji telah memenuhi syarat normalitas data.

Tabel 6. Hasil Uji Multikolinearitas

\begin{tabular}{|c|c|c|c|}
\hline \multicolumn{4}{|c|}{ Coefficients ${ }^{a}$} \\
\hline \multirow{2}{*}{\multicolumn{2}{|c|}{ Model }} & \multicolumn{2}{|c|}{ Collinearity Statistics } \\
\hline & & Tolerance & VIF \\
\hline & $\mathrm{X} 1$ & 974 & 1,027 \\
\hline & $X 2$ & ,974 & 1,027 \\
\hline
\end{tabular}

a. Dependent Variable: $Y$ 
Berdasarkan Tabel 6, nilai tolerance sebesar 0,974 dan variance inflation factor (VIF) sebesar 1,027 sehingga tidak ada variabel bebas yang nilai tolerance lebih dari 0,1 atau variance inflation factor (VIF) kurang dari 10, maka disimpulkan bahwa tidak ada multikolinearitas antara variabel bebas dalam model regresi.

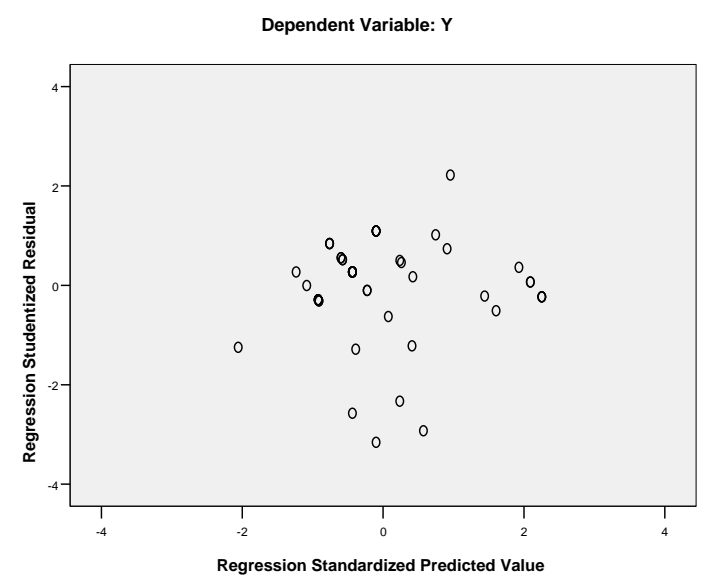

Gambar 2. Hasil Uji Heteroskedastisitas

Hasil uji Heteroskedastisitas sesuai pada Gambar menunjukkan sebaran data tidak membentuk pola tertentu, maka dinyatakan tidak mengandung heteroskedastisitas.

\section{Analisis Regresi Linier Berganda}

Tabel 7. Hasil Analisis Regresi Berganda

\begin{tabular}{|c|c|c|c|c|c|c|}
\hline \multirow{2}{*}{\multicolumn{2}{|c|}{ Variabel }} & \multicolumn{2}{|c|}{$\begin{array}{l}\text { Unstandardized } \\
\text { Coefficients }\end{array}$} & \multirow{2}{*}{$\begin{array}{c}\text { Standardized Coefficients } \\
\text { Beta } \\
\end{array}$} & \multirow[t]{2}{*}{$\mathbf{t}$} & \multirow[t]{2}{*}{ Sig. } \\
\hline & & B & Std. Error & & & \\
\hline & (Constant) & 5,428 & 0,815 & & 6,664 & 0,00 \\
\hline Kepem & impinan partisipatif & 0,418 & 0,034 & 0,848 & 12,143 & 0,00 \\
\hline Ling & xungan kerja fisik & 0,202 & 0,038 & 0,376 & 5,379 & 0,00 \\
\hline $\begin{array}{l}\mathrm{R} \\
\mathrm{R}^{2} \\
\mathrm{~F}_{\text {hitung }} \\
\text { Sig F Fitung }\end{array}$ & $\begin{array}{l}=0,870 \\
=0,758 \\
=79,718 \\
=0,000\end{array}$ & & & & & \\
\hline
\end{tabular}

Dari hasil analisis regresi pada tabel di atas dapat disusun persamaan regresi sebagai berikut:

$\mathrm{Y}=5,428+0,418 \mathrm{X} 1+0,202 \mathrm{X} 2$

Berdasarkan nilai a, b1, b2, diperoleh persamaan garis regresi linear berganda antara kepemimpinan partisipatif, lingkungan kerja fisik terhadap semangat kerja karyawan memberikan informasi bahwa:

a. $a=5,428$ artinya apabila tidak ada perhatian terhadap kepemimpinan partisipatif, lingkungan kerja fisik maka skor semangat kerja karyawan adalah rata-rata sebesar 5,428. 
b. b1 = 0,418 artinya apabila lingkungan kerja fisik(X2) dianggap konstan maka meningkatnya skor kepemimpinan partisipatif (X1) sebesar satu satuan akan diikuti oleh meningkatnya skor semangat kerja karyawan (Y) rata-rata sebesar 0,418.

c. b2 = 0,202 artinya apabila kepemimpinan partisipatif (X1) dianggap konstan maka meningkatnya lingkugan kerja fisik (X2) sebesar satu satuan akan diikuti oleh meningkatnya skor semangat kerja karyawan (Y) sebesar 0,202.

Untuk menguji nyata-tidaknya pengaruh variabel bebas kepemimpinan partisipatif (X1) dan lingkungan kerja fisik(X2) secara simultan terhadap variabel terikat semangat kerja karyawan (Y) dilakukan uji F.

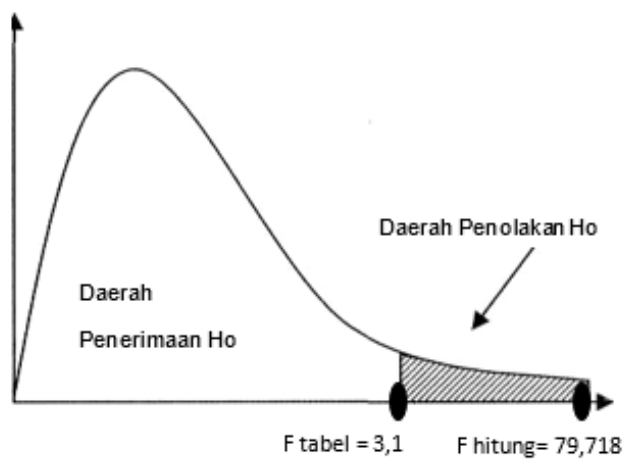

Gambar 3. Kriteria pengujian F

Kriteria Pengujian

1) Jika F hitung > F tabel $(3,1)$ maka Ho ditolak, berarti pengaruh tersebut signifikan.

2) Jika F hitung $\leq \mathrm{F}$ tabel $(3,1)$ maka Ho diterima, berarti pengaruh tersebut tidak signifikan.

Sesuai hasil perhitungan F-test diperoleh F-hitung = 79,718 dibandingkan dengan nilai Ftabel $=3,1$, maka ternyata nilai Fhitung lebih besar dari nilai F-tabel, dan F-hitung berada pada daerah penolakan HO. Oleh karena itu, HO ditolak dan Ha diterima. Ini berarti bahwa pada taraf $\alpha=5 \%$ secara simultan kepemimpinan partisipatif(X1) dan lingkungan kerja fisik (X2) memiliki pengaruh positif yang signifikan terhadap semangat kerja karyawan (Y). Sehingga hipotesis yang berbunyi "gaya kepemimpinan partisipatif (X1), lingkungan kerja fisik (X2) berpengaruh positif dan signifikan terhadap semangat kerja karyawan (Y), teruji ke benarannya atau diterima.

Uji T digunakan untuk menguji signifikasi masing-masing koefisien regresi, sehingga diketahui apakah secara parsial kepemimpinan partisipatif berpengaruh terhadap semangat kerja karyawan adalah memang nyata terjadi (signifikan) atau hanya diperoleh secara kebetulan. 


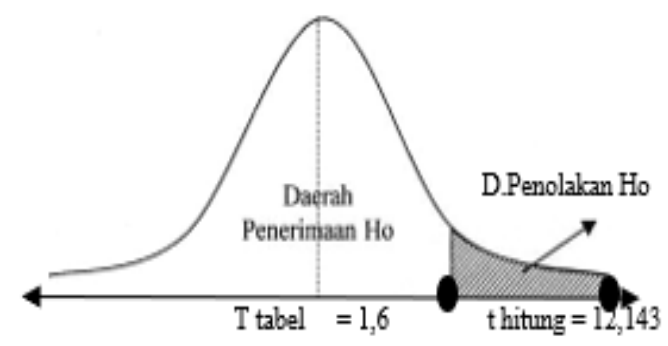

Gambar 4. Kriteria t-test

Kriteria Pengujian

1) Jika t-hitung $\leq$ t-tabel $(1,6)$ maka Ho ditolak, berarti pengaruh tersebut signifikan.

2) Jika t-hitung > t-tabel $(1,6)$ maka Ho diterima, berarti pengaruh tersebut tidak signifikan.

Berdasarkan gambar 4 tampak jelas bahwa: apabila nilai t-hitung $=12,143$ dibandingkan dengan nilai t-tabel $=1,6$, maka ternyata nilai t-hitung lebih besar dari nilai ttabel dan t-hitung berada pada daerah penolakan HO, sehingga HO ditolak dan Ha diterima. Ini berarti bahwa apabila lingkungan kerja fisik (X2) konstan, secara statistika pada taraf kepercayaan $(\alpha)=5 \%$, gaya kepemimpinan partisipatif $(X 1)$ berpengaruh positif dan signifikan terhadap semangat kerja karyawan (Y). Hipotesis yang berbunyi gaya kepemimpinan partisipatif (X1) berpengaruh positif dan signifikan terhadap semangat kerja karyawan (Y) adalah teruji kebenarannya (Ho ditolak).

Untuk mengetahui apakah secara parsial lingkungan kerja fisik berpengaruh terhadap semangat kerja karyawan adalah memang nyata terjadi (signifikan) atau hanya diperoleh secara kebetulan maka langkah-langkah uji statistiknya adalah:

a. Membuat Formulasi Hipotesis

H0 : b2 $=0$, berarti tidak ada pengaruh lingkungan kerja fisik (X2) secara parsial terhadap semangat kerja karyawan (Y)

$\mathrm{Ha}: \mathrm{b} 2>0$, berarti ada pengaruh positif dan signifikan lingkungan kerja fisik (X2) secara parsial terhadap semangat kerja karyawan (Y)

b. Penentuan Statistik Tabel

Sesuai dengan hipotesa alternatif (Ha). Dalam penelitian ini digunakan $\alpha$ (taraf kepercayaan $)=5 \%$ dan df $($ degrrees of freedom $=$ derajat bebas $)=n-k-1=54-3-1=50$, sehingga besarnya ttabel $=\mathrm{t}(\alpha, \mathrm{df})$ yang dicari adalah $\mathrm{t}(5 \%, 50)$. Besarnya $\mathrm{t}(5 \%, 50)$ adalah 1,6 .

c. Menghitung t-hitung

Diketahui: 
t-hitung $=5,379$

Berdasarkan Gambar 4 tampak jelas bahwa: apabila nilai t-hitung $=5,379$ dibandingkan dengan nilai ttabel $=1,6$, maka ternyata nilai t-hitung lebih besar dari nilai ttabel dan t-hitung berada pada daerah penolakan HO, sehingga $\mathrm{HO}$ ditolak dan Ha diterima. Ini berarti bahwa apabila kepemimpinan partisipatif (X1) konstan, secara statistika pada taraf kepercayaan $(\square)=5 \%$, lingkungan kerja fisik (X2) berpengaruh positif dan signifikan terhadap semangat kerja karyawan (Y). Hipotesis yang berbunyi lingkungan kerja fisik (X2) berpengaruh positif dan signifikan terhadap semangat kerja karyawan (Y) adalah teruji kebenarannya (Ho ditolak).

\section{Simpulan}

Berdasarkan hasil analisis data dan pembahasan maka dapat disimpulkan bahwa:

1. Gaya kepemimpinan partisipatif berpengaruh positif dan signifikan secara parsial terhadap semangat kerja karyawan pada CV. Dinayu Konveksi Ubung dengan koefisien regresi sebesar 0,418 .

2. Lingkungan kerja fisik berpengaruh positif dan signifikan secara parsial terhadap semangat kerja karyawan pada CV. Dinayu Konveksi Ubung dengan koefisien regresi sebesar 0,418.

3. Hasil F-test diperoleh F-hitung adalah 79,718 lebih besar dari F-tabel sebesar 3,1 yang berarti memang benar ada pengaruh positif dan signifikan secara simultan antara kepemimpinan partisipatif dan lingkungan kerja fisik terhadap semangat kerja karyawan pada CV. Dinaya Konveksi Ubung.

\section{Saran-Saran}

Berdasarkan hasil penelitian dan pembahasan tersebut di atas maka dapat penulis sarankan bagi manajemen perusahaan sebagai berikut:

1. Untuk meningkatkan kualitas penerapan gaya kepemimpinan partisipatif pada perusahaan, maka perlu adanya peningkatan pada indikator yang masih dianggap kurang oleh responden, yaitu cara berkomunikasi, oleh karena itu pimpinanhendaknya mengevaluasi diri dalam menerapkan cara cara berkomunikasi yang sesuai dengan bawahan, sehingga informasi yang akan disampaikan dapat diterima dengan baik oleh bawahan.

2. Pada lingkungan kerja fisik diketahui nilai rata-rata yang paling rendah dinilai oleh responden adalah kebersihan dan keamanan, oleh karena itu dari segi kebersihan perusahaan agar menempatkan lebih banyak tempat sampah pada ruang kerja untuk menempatkan potongan sisa kain yang berceceran. Dari segi keamanan perusahaan bisa menambah adanya cctv agar karyawan merasa aman dalam bekerja. 
3. Bagi peneliti berikutnya dapat menambahkan variabel bebas yang mempengaruhi semangat kerja karyawan, seperti kompensasi.

\section{Daftar Pustaka}

Agusman. 2004. Pengaruh Gaya Kepemimpinan, Motivasi dan Lingkungan Kerja Terhadap Kinerja Sekretariat Daerah Kabupaten Kepulauan Riau. Tesis Program Pasca Sarjana Magister Manajemen Universitas Gajah Mada Yogyakarta.

Dessler, Gary. 1993. Manajemen Personalia. Jakarta. Penerbit Erlangga

Dharma, Agus. 2003. Manajemen Supervisi: Petunjuk Praktis Bagi Para Supervisor.Edisi Revisi. Cetakan kelima. Jakarta: Raja Grafindo Persada

Flippo, Edwin B. 1995. Manajemen Personalia. Penerjemah Moh. Masud, Erlangga Jakarta. Gomes, Faustino Cardoso. 1995. Manajemen Sumber Daya Manusia. Andi Ofset.Yogyakarta. Hasibuan, Sayuti. 2000. Manajemen Sumber Daya Manusia. Edisi Revisi. Bumi

Hasibuan, H. Malayu. SP. 2007. Manajemen Sumber Daya Manusia. Jakarta: Bumi Aksara Kartini, Kartono. 2005. Pemimpinan dan Kepemimpinan. PT. Raja Grafindo Persada:Jakarta. Kusuma Dewi, Sari., Frianto, Agus. 2013. Pengaruh Lingkungan Kerja Terhadap Kinerja Karyawan Melalui Motivasi. Jurnal Ilmiah Manajemen, Vol. 1 No. 4.

Luksono Pramudito dan Askar Yunianto. 2009. Pengaruh Kepemimpinan Dan Motivasi Terhadap Kinerja Dengan Komitmen Organisasional Sebagai Mediasi (Studi Pada Perangkat Desa SeKecamatan Batang Kabupaten Batang), TEMA Vol. 6 Hal 1-18

Sugiyono. 2004. Metode Penelitian Bisnis. Bandung: Alfabeta

Sumarsono, Sonny. 2004. Metode Riset Sumber Daya Manusia. Yogyakarta : Graha Ilmu 